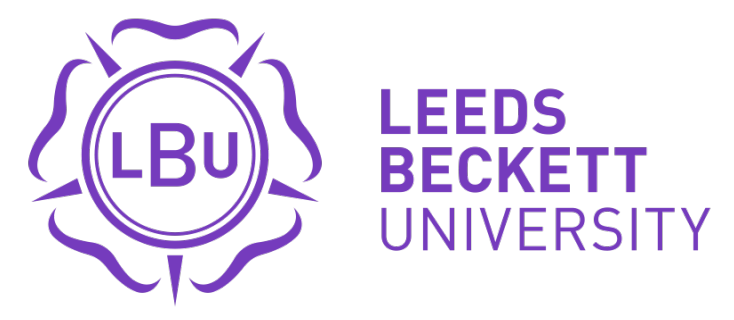

Citation:

Doney, $\mathrm{P}$ and Evans, R and Fabri, M (2014) Keeping creative writing on track: Co-designing a framework to support behavior change. Lecture Notes in Computer Science (including subseries Lecture Notes in Artificial Intelligence and Lecture Notes in Bioinformatics), 8517 L (PART 1). 631 642. ISSN 0302-9743 DOI: https://doi.org/10.1007/978-3-319-07668-3_61

Link to Leeds Beckett Repository record:

https://eprints.leedsbeckett.ac.uk/id/eprint/1772/

Document Version:

Article (Accepted Version)

The aim of the Leeds Beckett Repository is to provide open access to our research, as required by funder policies and permitted by publishers and copyright law.

The Leeds Beckett repository holds a wide range of publications, each of which has been checked for copyright and the relevant embargo period has been applied by the Research Services team.

We operate on a standard take-down policy. If you are the author or publisher of an output and you would like it removed from the repository, please contact us and we will investigate on a case-by-case basis.

Each thesis in the repository has been cleared where necessary by the author for third party copyright. If you would like a thesis to be removed from the repository or believe there is an issue with copyright, please contact us on openaccess@leedsbeckett.ac.uk and we will investigate on a case-by-case basis. 


\title{
Keeping creative writing on track: Co-designing a framework to support behavior change
}

\author{
Paul Doney ${ }^{1}$, Rebecca Evans ${ }^{2}$ and Marc Fabri ${ }^{1}$ \\ ${ }^{1}$ Leeds Metropolitan University, United Kingdom \\ \{p.doney, m.fabri\}@leedsmet.ac.uk \\ ${ }^{2}$ Minty Man Limited, United Kingdom \\ towritetrack@gmail.com
}

\begin{abstract}
The application of persuasive technology in web-based and mobile phone-based systems is well established, particularly in the health domain. However, a greater understanding of the effectiveness of the techniques deployed is needed to facilitate the successful transfer of research findings into practical applications. The context explored here is that of creative writing and the potential use of persuasive technology to foster and support a productive writing routine. Employing a user-centered design approach, we conducted surveys and a co-creation workshop with writers. Goal setting and regular writing, combined with self-monitoring, were key indicators of an effective writing practice. Group and mentor support were also highlighted. Based on our findings, we developed the architecture for a mobile personal writing coach. We evaluated the architecture against existing frameworks, finding good congruence. This supports our long-term goal of creating a universal framework, applicable to a wider range of behavior change interventions, domains and users. The design considerations reported in this paper go some way towards that goal.

Keywords: Behavior Change · Goal Setting · Design Thinking · User-Centered Design $\cdot$ Co-Design $\cdot$ Methodology
\end{abstract}

\section{Introduction}

The application of persuasive technology to support positive behavior change has had significant success in the health domain with symptom trackers and management systems; in particular for physical and mental health, with specific examples for smoking cessation, weight loss and exercise [32][16]. Another arena has been reducing energy consumption [6]. These studies have resulted in a number of models for future systems to follow, whether that be from the perspective of underlying psychological theories, the use of persuasive interface design techniques [9] or architecture of functional components [23]. In parallel with this research effort, the availability of smart phones has facilitated a growth in productivity and tracking applications. These applications reflect many of the characteristics of those developed as part of research programs, although many have been developed within a commercial environment such as HealthMonth [12] and Runkeeper [29] and Lift [17]. 
In this paper we report on the design of a framework for facilitating positive behavior change in creative writers, applying a user-centered approach. The research with users was undertaken to support the design phase of the proposed development of a mobile website, which will function as a personal writing coach. The goal of the website will be to assist aspiring and active writers to improve their writing practice and consequently meet their writing goals.

\section{Background}

The UK has an established and thriving creative writing sector, with 150 university level courses, and many thousands of short uncredited courses offered by organizations like Arvon [4] which has been running courses since 1968, The Guardian [11] and Faber [8] as well as short courses run in local libraries, colleges and by organizations like WEA [33]. Other tools to support aspiring and active writers include magazines like Writing Magazine [30], Writers Digest [7] and Mslexia [25]. Further to this, there are websites and apps offering advice, writing prompts, and allowing writers to post work and get feedback from writing communities; examples include National Novel Writing Month [26], Writers Café [3] and Wattpad [31].

Despite the creative writing sector offering such a variety of tools for supporting writing, our research identified a gap in the provision for supporting positive behaviors related to managing writing goals and promoting effective routines. Both of which could be offered through persuasive technology. This presented an opportunity for practical innovation and the proposal for application architecture to meet this gap. Given this, our work reported here is driven by the hypothesis that a route to writing success is based on developing a regular writing routine which is goal-based and measurable. Core to this is a focus on positive behavior change and fostering habits which can be tracked by the individual writer.

The suggestion that goal setting and habit change could be a more effective route to writing success than, for example, generating ideas, was tested with a large group of writers through a series of online questionnaires, a workshop using personas, and a small sample of paper-based writing trackers. This paper reports the results of this research and proposes a practical framework for behavior change and goal setting for creative writers. We then develop this framework into the application architecture of a mobile website-based personal writing coach called "Write-Track" [34].

\section{$3 \quad$ Related Work}

The desire to drive positive behavior change supported by technology is evident from meta studies examining web based systems [32] and mobile devices [27]. In persuasive technology research there has been a concerted attempt to apply established models of behavior change, including the Trans-Theoretical Model (TTM) [14], Theory of Planned Behavior (TPB) [1] and Social Cognitive Theory (SCT) [5] - either individually or in combination. TPB has been identified as a relatively successful online intervention model [32], but Michie et al [24] observed that even when inter- 
ventions have been underpinned by established models, this is often done so minimally and without due consideration being given to all potential variables. From a system design perspective, this critique is understandable as the models in question are typically an attempt to illustrate interactions between various factors and therefore do not provide a clear framework for development. To test whether a system applies a model, an examination of the variables inherent within them can provide a framework.

Michie's Behavior Change Wheel [24] labels the three high level influences as Motivation, Capability and Opportunity. These closely mirror the work of Fogg [9], who similarly considered Motivation and Ability as key, but introduces the importance of Triggers. Triggers raise motivation or ability to the level where an individual is able to perform the target behavior; alternatively a trigger may simply act to nudge an individual who already has the ability and motivation but just needs a timely reminder [9]. SCT and TPB also present the path to behavior change as one that is dependent on a triad of influences, with SCT drawing attention to opportunity derived from the impact of environmental and personal factors [5] and TPB considering motivation in the guise of personal attitudes and perceived norms [1]. Both focus on selfefficacy as the key trigger for promoting a target behavior. In contrast, TTM is hierarchical and sequential, which offers designers a model that can more easily be transferred into a development framework or indeed an automated interaction. TTM identifies seven stages of change starting from a position of ignorance, through preparing for behavior change, through action and onto long term maintenance [14].

Whilst accepting the importance of behavioral models as an influence on system designers, some have sought to extend these to develop a framework that encompasses the experience of software systems design [13][28]. This move towards drawing lessons from different domains in pursuit of effective guidance for systems developers seems natural, with systems for behavior change being increasingly examined from an HCI perspective by commentators with a background in digital design.

Lockton et al [20] observed that design to influence behavior is not a domain specific pursuit and that attempts have been made in various domains such as architecture, medicine and web design to develop 'How-To' guides. Lockton offers the Design with Intent Toolkit to help direct designers of behavior change systems [19], presenting lessons learned from a multitude of domains. More recently Lockton et al [21] have begun to develop a set of behavioral heuristics as a means of defining further guidance. Anderson [2] offers a card-based 'Mental Notes' reference system for interfaces designers, drawing from psychology to capture insights into human behavior that can be applied to the design of websites or other software applications.

The adoption of web-based delivery to support behavior change has the advantage of being dynamic and unbiased, but all too often initiatives focus on the provision of information and underuse the technological potential [18]. The emergence of more interactive applications that include tracking, triggers, reminders and communication demonstrate that there is a clear shift towards exploiting technology more fully [15][27]. Extending this progression from theory to practical application, guidelines have been offered for design principles aimed at behavioral intentions [10], design patterns to influence user behavior [19] and persuasive information architecture [23]. 


\section{$4 \quad$ Research and Investigation}

Practical experience of working with writers indicated that there may be a gap in support available that is aimed at fostering an effective writing routine. It was therefore hypothesized that a route to writing success is based on developing a regular writing routine, which is goal-based and measurable. This hypothesis was tested with writers through a series of online questionnaires, a workshop and a small sample of paperbased personal diary studies.

\subsection{Scoping Questionnaire}

The aim of the questionnaire was to explore whether goal setting and a regularized writing routine offered an effective route to writing success, when compared to other techniques and approaches. Respondents were recruited by using the Twitter feed of co-author Rebecca Evans and the Arvon Foundation. Both these feeds are used to communicate with writers and in particular those that have attended an Arvon creative writing course. The use of Twitter potentially narrowed the target audience from all creative writers to those that are actively using technology. Using this approach, a convenience sample of 142 writers responded to the questionnaire which was delivered via Survey Monkey in two tranches between January and June 2013.

Results. 85\% of respondents wanted to write more regularly and, of these, 90\% wanted to write every day. Main obstacles to this were failure to develop good writing practice (61\%) and difficulty finishing a project (57\%). Key reasons were lack of time (56\%) and lack of discipline (50\%). In contrast, $76 \%$ of respondents found that ideas came to them easily, and $71 \%$ replied they found it easy to find inspiration. Main sources for inspiration were deadlines (75\%), encouragement (61\%) and competitions (35\%); with on-going motivation being derived from writing groups (53\%) potential success in competitions (51\%) and going on a writer retreat (45\%). Writers measure the success of achieving goals by completing a full project (50.7\%), subjective evaluation (45.8\%) and getting published (45.1\%). Only 4.2\% of respondents said they do not measure success in any way. Of the 97 participants who responded to whether they would be interested in using technology to improve their writing practice, $64 \%$ said they'd like to, $22 \%$ said no and 14\% said they don't know.

\subsection{Workshop}

To seek further insights into potential responses to the problem domain, whether that be technological or otherwise, a structured workshop was devised. The aim of the workshop was to gain a deeper understanding of the strategies and methods employed by writers when confronted with particular challenges. In advance of the workshop 11 personas were developed, capturing the lives and characteristics of writers that were not meeting their goals. Each persona consisted of a detailed one-page description. Below are brief summaries of three of the personas: 
- Molly is maddened by motherhood - Molly has two children under five, a part time job, and spends her spare time running a busy household. She has always written and is part way through a novel - she feels a loss of identity by not being able to realize her creativity.

- Dan's difficult second novel - Dan has a two book deal with a publisher. It took him ten years to write the first book, now he needs to deliver the second in 18 months. He's scared he can't write this book and is worried he is a one hit wonder.

- Master of Arts Madeline - Madeline has completed her MA in creative writing she's got talent, great ideas, a short story collection and a first draft of a novel. She thrived in the college environment - now she needs to develop the practice on her own and is struggling without external deadlines.

In the first half of the workshop, participants formed groups of 2-4 and drew on their own experience to empathize with the aspirations and challenges that each persona presented. Then they identified a range of potential interventions to address the frustrations of their persona. These were narrowed down to the two favored interventions for each participant group. Participants were then introduced to the Fogg Behavior Grid [9] prior to being asked to examine the interventions they had identified and collectively place the identified interventions into the most appropriate grid cells. Each group was then provided with an information card about the grid cells relevant to their interventions and asked to re-examine their chosen interventions and develop suitable behavior change strategies, considering triggers, motivation and ability.

The workshop format was trialed with a small group of postgraduate students from a Creative Technology course. No changes were made following the trial. The actual workshop took place during May 2013 with 24 active writers as participants, forming 8 groups. Each group considered a different persona.

Results. Groups generally identified with their personas well and had no problems generating ideas for interventions. For example, the suggestions for 'Madeline' were:

- Get together with the course colleagues

- Enter competitions to provide deadlines

- Look for enthusiasm and encouragement, be around nice people (e.g. at festivals)

- Read out work at live shows where audience members perform at the microphone

- Set realistic goals

- Do small pieces of work at a time

The two favored interventions developed from above suggestions and then placed onto the Behavior Grid were to a) join a support group (Blue Dot - do a familiar behavior one time), and b) seek feedback from a mentor (Green Span - do behavior for a period of time). Overall, interventions proposed by the groups could be split into four broad categories:

1. Lifestyle changes to overcome difficult hurdles (6)

2. Goal setting as a focus for motivation and/or provision of a trigger to action (4)

3. Feedback in the form of social interaction or from experts as mentoring (4) 


\section{Improved time management to release time for writing (2)}

Once all groups narrowed their suggestions down to the two favored interventions each, using the Fogg Behavior Grid as a reference point, feedback (13 occurrences) and goal setting (5) emerged as key interventions. Suggestions for lifestyle changes, although popular during the initial brainstorm, played only a minor role in the end.

\subsection{Personal Diary Study}

At the same time, we ran a personal diary study with 15 writers during one week in May 2013. The purpose of the study was to explore qualitatively what types of goals writers set and how they monitored their progress against them. We chose a personal diary method because this generally yields high accuracy when compared other methods, such as questionnaires or retrospective interviews. The diary study was presented as a paper-based writing tracker. Participants were asked to record, over five consecutive days, any goals they had set themselves and their progress against them. Volunteer participants were recruited from attendees at a writing retreat and were a mix of ages and genders. At the beginning of the week they were asked if they had set any goals for their writing, and what these were. Each day the writers were asked 3 questions: 1) Did you write today? 2) How did it go? 3) How did you feel about your writing today? At the end of the week they were asked if they had met their goals, whether and how they usually measured goals, if it is useful to do so, whether they found it useful to keep track of their writing and how they felt about it.

Results. Allowing writers to articulate their goals without a prompt generated a range of different goals. Some were very specific and number based, therefore easy to measure: 15,000 - 20,000 words per week; 3,000 - 5,000 words a day; 2-4 chapters of a book. Others said they planned on completing comedy sketches or the first draft of a novel or new draft of a manuscript. Though these are not defined numerically they are still closed goals with specific end points.

Some writers focused on planning their work, rather than writing a certain amount, for example outlining a novel, plotting a novel and writing the first few chapters. Others looked at editing a radio play or a short story, or reviewing and restructuring a draft of a novel. These types of goals may be complex to measure, but there is still a specific end point so writers can say whether they achieved it or not.

Writers were asked about the usefulness of setting goals and many found it a positive experience: "It has become like a diary record and allowed me to reflect on how my writing picked up pace." Another said: "[Goals] help me focus. I feel better about myself when I meet them at the end of each day and I am motivated to set more."

There was an opportunity for writers to comment on the act of tracking itself. Again the role of motivation was mentioned: "Keeping track was an additional motivation." This was especially the case when writers looked back over the week. "It's interesting to see the cumulative effect through a week of responses to writing. It only takes minutes and once it is established as a habit I imagine it could become a valuable tool for supporting work." Another found that poor past performance actually 
made them write more: "It showed me that I am goal driven because [when] I felt that I am failing to reach my target I worked and forced myself more."

The structure of the tracker worked for writers, "I found the 3 part structure very simple and it made me see what I'd actually done." With some saying they would like to continue with the practice: "I'll be incorporating this in my daily practice from now on." Another saying: "I wish I'd done it years ago!" Finally one writer suggested how the tracker could be extended: "I could imagine having tracker support groups getting together to share findings - more about the reflection on the process than the amount of words completed or hours spent writing."

\subsection{Final Questionnaire}

A final questionnaire was devised, with a particular focus on exploring writing goals and habits. Twitter was again utilized to generate a convenience sample and the questionnaire was delivered using Survey Monkey, with 183 writers taking the survey during September 2013.

Results. Key findings were that $54 \%$ of writers set themselves goals, with only $16 \%$ being clear that they did not motivate themselves at least partially through goal setting. Of those that set goals $28 \%$ actively tracked progress, with $45 \%$ undertaking at least some limited monitoring. When asked to identify goals, the most popular were:

- Measurable closed goals such as time spent, number of pages written (per week, month), or number of words per day, week, fortnight or month (examples given included 500, 800, 1,000, 1,500, 4,500, and 5,000)

- Goals based around sections of writing or parts of a project, such as completing a chapter, scene, outline, article, poem, collection, novel (per day/week/month etc)

- Some writers set annual goals or aspirations such as submitting to agents, sharing with friends or peers

- Others saw the goal as an achievement of a routine, or meeting a deadline for a competition or from other external sources like publishers or agents

When selecting goals from a pre-defined list, the completion of part (56\%) or a full (53\%) project were the most popular; with both external deadlines (52\%), words written $(45 \%)$ and internal (45\%) deadlines featuring strongly. The potential to share goals was questioned and an equal (32\%) percentage of respondents were inclined towards sharing as those that felt their goals should be kept private. However, a greater proportion of those that were undecided were inclined (20\%) towards sharing than those that were dis-inclined (13\%). Only $3 \%$ said they had no goals.

\subsection{Discussion}

Writing regularly emerged as a key ingredient of having a good writing practice. The main barrier to this, interestingly, is not lack of ideas or inspiration, but lack of time and discipline. Questionnaire results clearly pointed towards goal setting and 
tracking of progress as a highly effective way of developing good writing practice. Interestingly, the tracker study revealed that the simple act of setting a goal can, for some, be enough to spur on writing - even without much tracking and follow-up. And the easier it is to set goals and track progress, the more likely it will become a habit.

Further, a focus on emotions as a key part of the goal setting emerged - it may not be just about the actual achievement but how people felt. It appears that setting writing goals increases feelings of well-being associated with achievement. There are many ways of measuring success in writing: from outlining a writing plan or completing a draft, over writing a set number of words per day to completing a project and getting published. What all these have in common is that they are easily measurable and characterized by set end points. The $2^{\text {nd }}$ questionnaire identified the importance of having easily trackable milestones and deadlines and ticked off when completed.

Both the workshop and the diary study provided evidence that peer support, peer feedback and joint activities can be strong motivators to increasing writing and forming new positive habits. The first questionnaire also pointed towards contact with other writers, in a regular group or during a residential, as a strong motivator for writing. The opportunity for reflection - on both writing process and progress - within a group emerged as a potential catalyst for fostering motivation and forming habits.

\section{Proposed Application Architecture}

Drawing on insights gained from our research, we developed a proposal for the application architecture of the personal writing coach. It was clear from engagement with writers that managing goals and gaining feedback were central elements. Our architecture aims to deliver the elements through four inter-connected components:

Goal Setting. Enables users to make personal commitments and help them develop regular habits. Users have the option to define goals for specific projects or for their writing in general. Goals can be open ended or closed, with defined deadlines such as submitting to a competition. Goals may be user-defined or selected from suggested popular goals. Reminders are sent to assist users track progress.

Tracking and Analysis. Tracking could be as simple as allowing users to log that they have written that day or monitor against their goals by ticking them off, for example writing for a certain time or completing a defined number of words. Over a period of usage it will help users recognize what stops them writing and helps them to develop good writing practice and the conditions that support it. The application aggregates collected data and feedback on how the community of users is performing.

Groups. By making a goal public, the user joins a group of people with the same goal and has some awareness of what other group members are doing. Groups provide a means for users to share their experience with others and gain feedback (either automated or personalized). Having public goals is seen to be a crucial component for 
success in helping writers to progress. Groups are set up around pre-set goals, for example: write five days a week; write 500 words a day; write for a competition.

Resources. A wealth of support material is already available to writers, and this section does not duplicate but instead manage and signpost users to reliable sources, thereby fulfilling a mentoring role (albeit in a passive way). Resources are searchable, give access to support materials and provide links to further information. This section will grow through the use of a moderated forum, providing opportunities for peer support and feedback. It will feature a facility allowing writers to create their own personalized scrapbook of resources containing notes, photos, links etc.

\subsection{The architecture in context}

To evaluate the proposed architecture we examined it with reference to the Fogg Behavior Model [9] and the information architecture design suggested by Marcus et al for the series of Machine designs [22][23]. We chose Fogg because the model it is perhaps the most discussed and referenced model in the Persuasive Technology domain. We chose Marcus' Machine because it too was developed using a user-centred approach albeit in a completely different domain, so any parallels would arguably point towards domain-transferable concepts and architecture components.

Fogg Behavior Model (FBM). Fogg [9] suggests that motivation and ability must combine at a level such that an effective trigger will prompt action in support of a target behavior. Notably, Fogg suggests that boosting motivation and ability should be considered secondary in any intervention, with the design of timely triggers being critical if the intervention is to be effective. In examining the Writing Coach proposal against FBM, a precise mapping was not expected as the design was developed pragmatically in a commercially oriented environment, rather than a research-driven one. However, tables 1 and 2 illustrate that the proposed architecture has high congruence:

\begin{tabular}{|l|l|}
\hline FBM Factor & Mapping to Personal Writing Coach \\
\hline Ability & $\begin{array}{l}\text { Users self-defined as writers or aspiring writers, } \\
\text { Resources to boost knowledge, Advice from peers and/or experts }\end{array}$ \\
\hline Motivation & Goal tracking and Encouragement from peers/ experts \\
\hline Trigger & Tracking data, Reminders, Peer comparisons \\
\hline
\end{tabular}

Table 1. Fogg Behavior Model Mapping (high level)

The FBM offers further granularity to the three main factors, and by mapping these to our Personal Writing Coach architecture, a more complete picture emerges.

\begin{tabular}{|l|l|l|}
\hline Factor & Factor Component & Mapping to Personal Writing Coach \\
\hline \multirow{2}{*}{ Ability } & Time & Lack of time was found to be the main barrier to writing \\
\cline { 2 - 3 } & Money & No significant mapping \\
\hline
\end{tabular}




\begin{tabular}{|l|l|l|}
\hline \multirow{5}{*}{} & Physical Effort & No significant mapping \\
\cline { 2 - 3 } & Brain Cycles & Provision of resources \\
\cline { 2 - 3 } & Social deviance & No significant mapping \\
\cline { 2 - 3 } & Non-routine & Ideas of others through direct contact or resources \\
\hline \multirow{4}{*}{ Motivation } & Pleasure/Pain & Meeting targets/ achieving goals \\
\cline { 2 - 3 } & Hope/Fear & Setting goals \\
\cline { 2 - 3 } & Acceptance/Rejection & Receiving positive feedback \\
\hline \multirow{3}{*}{ Triggers } & Spark & Writing prompts \\
\cline { 2 - 3 } & Facilitator & Mentor support \\
\cline { 2 - 3 } & Signal & Reminders, results of comparative analysis \\
\hline
\end{tabular}

Table 2. Fogg Behavior Model Mapping (detailed level)

By mapping the application at this finer level of granularity some gaps can be seen. It could be argued that the application holistically supports a planned approach to writing and therefore aids time and lifestyle management, but there are no explicit aspects of the application that address the broader aspects of an individual's personal situation. Two of the elements of Ability, namely physical effort and social deviance, did not find a map in the context of creative writing. There is however a strong mapping against all aspects of motivation, particularly in support of pleasure, hope and acceptance. There are no elements in the application that explicitly focus on pain, fear, or rejection; although the peer support mechanisms could result in feedback that focuses on the predicted impact of not achieving set goals. The reminders and tracking analysis provide reliable signal triggers and the communication with other users could result in the provision of facilitator triggers, but this is considered to be too unreliable to provide a significant mapping. Fogg [9] notes that spark triggers could be considered annoying, so the absence of a strong mapping here is considered appropriate.

\section{Aaron Marcus and Associate's (AM+A) Machine Architecture}

AM +A's proposal for a Health Machine [22] provides an in-depth design overview including a proposed generic information architecture for the health domain. This builds on an earlier proposal for a Green Machine [23] aimed at facilitating environmentally sustainable behavior. Whilst both these initiatives vary from the context of creative writing, the architecture itself lends itself to adaptation to other domains. AM+A's architecture offers 5 high level components, as illustrated in Table 3. A further $6^{\text {th }}$ level was omitted as it was considered too context-specific.

In contrast to the expectations with regard a mapping to the FBM, it was expected that the information architecture proposed for the personal writing coach would have strong links with that proposed by $\mathrm{AM}+\mathrm{A}$, primarily as both have been developed against a background which includes the presence of many similar applications. The notable exception is AM+A's proposal for a My Challenges component. AM+A propose that users should be provided games and a reward-based system as part of their application. This gamification can be found in many on-line environments, but nothing emerged during the design stage of the personal writing coach to suggest that 
gamification techniques would be well received. Notably, compared to FBM the writing coach architecture omits any aspects that target motivation through the negative emotions of pain, fear and rejection. Somewhat related to this, AM+A propose that predicted outcomes based on current practice should be included as part of $\mathrm{My} \mathrm{Fu}-$ ture, potentially illustrating an unwelcome, and painful, future.

\begin{tabular}{|l|l|}
\hline Machine Component & Mapping to Personal Writing Coach \\
\hline My Condition - tracks exercise, weight, food, etc. & Tracking and comparative analysis \\
\hline My Future - goal setting \& visualization of goals & Goal Setting and dreams \\
\hline My Tips - recommendations \& user guidance & Resources and personal scrapbook \\
\hline My Challenges - game-based activities to educate & No significant mapping \\
\hline My Friends - social support \& communication & Group membership and communication \\
\hline
\end{tabular}

Table 3. Machine Architecture Mapping

\section{Conclusions}

The hypothesis that a route to writing success is based on developing a regular writing routine which is goal-based and measurable, was tested through the application of a user-centered co-design process. The hypothesis was supported by the combined results from the questionnaires and workshops that were delivered. The design process was also used to devise a framework for a mobile website to support positive behavior change, through the application of persuasive technology. Website development is currently underway [34] and the next stage of our work will be test and evaluation.

The framework that emerged was evaluated by completing a mapping exercise, comparing it with models by Fogg [9] and Marcus [22]. Overall the mapping provided good model congruence. While there was some variance in frameworks, these were minor, indicating that models developed primarily in a health context are transferrable to novel domains. This supports our long-term goal of creating a universal framework, applicable to a wide range of behavior change interventions and domains.

\section{$7 \quad$ References}

1. Ajzen, I.: The Theory of Planned Behavior. in Lange, Kruglanski, \& Higgins (eds.) Handbook of Theories of Social Psychology. London, SAGE Publications. (2012)

2. Anderson, S. P.: Seductive Interaction Design. Berkley, New Riders. (2011)

3. Anthemion Writer's Cafe, http://www.writerscafe.co.uk

4. Arvon Foundation, http://www.arvonfoundation.org

5. Bandura, A.: Social Cognitive Theory. In Lange, Kruglanski \& Higgins (eds.) Handbook of Theories of Social Psychology. London, SAGE Publications. (2012)

6. Cowley, B., Moutinho, J. L., Bateman, C. \& Oliveira, A.: Learning principles and interaction design for 'Green My Place'. Entertainment Computing, 2, 103-113. (2011)

7. Writer's Digest, http://www.writersdigest.com

8. Faber Academy, http://www.faberacademy.co.uk 
9. Fogg, B. J.: A behavior model for persuasive design. Proceedings of the 4th International Conference on Persuasive Technology. Claremont, California, ACM. (2009)

10. Gotsis, M., Wang, H., Spruijt-Metz, D., Jordan-Marsh, M. \& Valente, T. W.: Wellness partners. JMIR Research Protocols, 2, e10-e10. (2013)

11. Guardian Writing http://theguardian.com/guardian-masterclasses/creative-writing-courses

12. Health Month, http://healthmonth.com

13. Hilgart, M. M., Ritterband, L. M., Thorndike, F. P. \& Kinzie, M. B.: Using Instructional Design Process to Improve Design and Development of Internet Interventions. $J$ of Medical Internet Research, 14, 98-115. (2012)

14. Kennett, D. J., Worth, N. C. \& Forbes, C. A.: The contributions of Rosenbaum's model of self-control and the transtheoretical model to the understanding of exercise behavior. Psychology of Sport \& Exercise, 10, 602-608. (2009)

15. Lau, P.W.C., Lau, E.Y., Wong, D. P. \& Ransdell, L.: A Systematic Review of Information and Communication Technology-Based Interventions for Promoting Physical Activity Behavior Change in Children and Adolescents. J of Med Int Res, 13. (2011)

16. Lehto, T., Oinas-Kukkonen, H.: Persuasive Features in Web-Based Alcohol and Smoking Interventions: A Systematic Review of the Literature. J Med Int Res, 13(19). (2011)

17. Lift, https://lift.do

18. Litvin, E.B., Abrantes, A.M. \& Brown, R.A.: Computer and mobile technology-based interventions for substance use disorders. Addictive Behaviors, 38, 1747-1756. (2012)

19. Lockton, D., Harrison, D. \& Stanton, N.A.: The Design with Intent Toolkit, ISBN 978-09565421-0-6. (2012)

20. Lockton, D., Harrison, D. \& Stanton, N. A.: The Design with Intent Method: A design tool for influencing user behavior. Applied Ergonomics, 41, 382-392. (2010)

21. Lockton, D., Harrison, D. J., Cain, R., Stanton, N. A. \& Jennings, P.: Exploring Problemframing through Behavioral Heuristics. IJ of Design, 7(1), 37-53. (2013)

22. Marcus, A.: The Health Machine: Mobile UX Design That Combines Information Design with Persuasion Design. DUXU - Theory, Methods, Tools and Practice. Springer. (2013)

23. Marcus, A. \& Jean, J.: Going Green at Home. Information Design J, 17, 235-245. (2009)

24. Michie, S., Van Stralen, M. M. \& West, R.: The behavior change wheel: A new method for characterising and designing behavior change interventions. Impl. Science, 6. (2011)

25. Mslexia, https://www.mslexia.co.uk

26. National Novel Writing Month, http://nanowrimo.org

27. Pagoto, S., Schneider, K., Jojic, M., Debiasse, M. \& Mann, D.: Evidence-Based Strategies in Weight-Loss Mobile Apps. American J of Preventive Medicine, 45, 576-582. (2013)

28. Ritterband, L. M., Thorndike, F. P., Cox, D. J., Kovatchev, B. P., Gonder-Frederick, L. A.: A Behavior Change Model for Internet Interventions. Ann. of Beh Med, 38, 18-27. (2009)

29. RunKeeper, http://runkeeper.com

30. Warners Writers Online, https://www.writers-online.co.uk/Writing-Magazine

31. Wattpad, http://www.wattpad.com

32. Webb, T. L., Joseph, J., Yardley, L. \& Michie, S.: Using the Internet to Promote Health Behavior Change. J of Medical Internet Research, 12. (2010)

33. Workers Education Association, http://www.wea.org.uk

34. Write-Track, http://www.write-track.co.uk 